This item was submitted to Loughborough's Research Repository by the author.

Items in Figshare are protected by copyright, with all rights reserved, unless otherwise indicated.

\title{
Preface: Nonlinear waves in fluids in honor of Roger Grimshaw on the occasion of his 80th birthday
}

PLEASE CITE THE PUBLISHED VERSION

https://doi.org/10.1111/sapm.12262

\section{PUBLISHER}

(c) Wiley

\section{VERSION}

AM (Accepted Manuscript)

\section{PUBLISHER STATEMENT}

This is the peer reviewed version of the following article: Preface: Nonlinear waves in fluids in honor of Roger Grimshaw on the occasion of his 80th birthday. Studies in Applied Mathematics, 142(3), pp. 215 - 218, which has been published in final form at https://doi.org/10.1111/sapm.12262. This article may be used for noncommercial purposes in accordance with Wiley Terms and Conditions for Use of Self-Archived Versions.

\section{LICENCE}

CC BY-NC-ND 4.0

\section{REPOSITORY RECORD}

Khusnutdinova, Karima, and Dmitry Pelinovsky. 2019. "Preface: Nonlinear Waves in Fluids in Honor of Roger Grimshaw on the Occasion of His 80th Birthday". figshare. https://hdl.handle.net/2134/37460. 


\title{
PREFACE: NONLINEAR WAVES IN FLUIDS IN HONOUR OF ROGER GRIMSHAW ON THE OCCASION OF HIS 80TH BIRTHDAY
}

\author{
KARIMA R. KHUSNUTDINOVA AND DMITRY E. PELINOVSKY
}

This special issue of Studies in Applied Mathematics and the one that follows are dedicated to Prof. Roger H. J. Grimshaw on the occasion of his eightieth birthday. Roger Grimshaw is a world-leading applied mathematician, one of those people who has shaped the modern state of the area of nonlinear waves in fluids, with particularly important applications in geophysical fluid dynamics and theoretical oceanography.

Roger Grimshaw was born on 13 December 1938 in Auckland, New Zealand. He graduated from Auckland University (B.Sc. 1960, M.Sc. 1961) and obtained his Ph.D from the University of Cambridge in 1964, under the supervision of Prof. F.G. Friedlander. His PhD dissertation was on the subject of "Topics in the theory of wave propagation". After completion of his PhD, Roger received the Fullbright Travel grant (1964) to take up a post-doctoral fellowship at the Courant Institute of Mathematical Sciences in New York University, followed by the Royal Society and Nuffield Foundation Commonwealth Bursary (1969) to be a Senior Visitor at the Department of Applied Mathematics and Theoretical Physics at the University of Cambridge.

Over the course of his career, Roger has held positions in Australia and the UK. In particular, he was a Senior Lecturer (1965 - 1969) and then Reader (1970 - 1985) in the Department of Mathematics of the University of Melbourne. Later, he was a Professor of Applied Mathematics in the School of Mathematics of the University of New South Wales (1982 - 1992) and Monash University (1992 - 1999), before coming to the Department of Mathematical Sciences of Loughborough University (2000 - 2013). He is currently a Visiting Professor at Loughborough University and the University of Exeter, and he is a Senior Research Associate in the Department of Mathematics at University College London.

Roger has served on the editorial boards of 15 journals, including as an Associate Editor for Studies in Applied Mathematics from 1990, and he has held positions of significant management responsibility, including as Head of Department at both the University of New South Wales and Monash University. He has supervised numerous PhD students and postdoctoral fellows, many of whom actively work in the area of nonlinear waves in fluids.

Roger's service to applied mathematics was recognised with his election to the Australian Academy of Science in 1990, the award of a Centenary Medal of Australia in 2002 and the ANZIAM medal of Australia in 2004, and his election as a Fellow of the Australasian Fluid 
Mechanics Society in 2012 and of the Australian Mathematical Society in 2014. Two international conferences took place in his honour: at Loughborough University in September 2012 and at University of Southern Queensland in November 2018.

Roger has published many seminal research papers at the cutting edge of his research field, starting with his first papers on slowly varying solitary waves [1, 2, 3, 4], internal gravitywave packets [5, 6], internal waves in stratified shear flows [7, 8] and in rotating ocean [9]. Notably, he has developed asymptotic schemes for the derivation of model nonlinear equations describing internal waves in a variable environment as well as wave-mean flow interaction; he has studied the nonlinear dynamics described by these model equations in detail, successfully using a combination of analysis and numerical simulations. Throughout his research, Roger has studied the formation and dynamics of various nonlinear coherent structures. Roger's results have formed the modern framework for the interpretation of many oceanic observations and modelling results.

Perhaps most significantly, Roger has carried out detailed and paradigm-forming studies of oceanic and atmospheric nonlinear internal waves. These studies include, in particular, resonant wave interactions [10, 11], wave generation by flow interaction with topography [12, 13], propagation of solitary waves and undular bores on oceanic shelves and in inhomogeneous media [14, 15, 16, 17], and the effects of background rotation [18, 19, 20, 21]. Roger has obtained important results on solitary waves accompanied by oscillatory tails [22, 23] and stronglyinteracting solitary waves [24, 25]. Despite his age, Roger is still very active in research on internal waves in stratified shear flows [26], oceanic internal solitary waves [27], undular bores [28], and tidal flows over topography [29].

The present issue focuses on modulation theory and other methods of analysis of classical nonlinear wave equations. The second issue will focus on the theory of nonlinear gravitycapillary and internal waves, effects of variable bottom topography and rotation, and related asymptotic and numerical methods.

The first four papers of this issue are devoted to Whitham modulation theory. In [30], modulation theory is used to construct approximate traveling dispersive shock wave solutions of the fifth-order $\mathrm{KdV}$ equation. The traveling waves are shown to be modulationally stable in the presence of sufficiently small third order dispersion. In [31], the authors develop a universal analytical description of dispersive shock waves generated in Riemann problems for a broad class of integrable and non-integrable nonlinear dispersive equations. Several representative, physically relevant examples are considered to illustrate the efficiency of the developed general theory. In [32], dispersive shock waves are considered in the defocusing radial nonlinear Schröodinger equation in two spatial dimensions. In [33], the authors relate a transition of Whitham equations from hyperbolic to elliptic cases to the "sign characteristic" of real eigenvalues of Hermitian matrix pencils. The theory is applied to the two-phase traveling wave solutions of coupled nonlinear Schrödinger equations. 
The other three papers of the issue are devoted to the study of nonlinear evolution equations with the help of various numerical and asymptotic methods. In [34], the authors study the defocusing nonlinear Schrödinger equation written in the hydrodynamic form through the Madelung transform. In order to resolve the major numerical challenges, the authors introduce a twoparameter family of extended Lagrangians, whose Euler-Lagrange equations are hyperbolic and accurately approximate NLS equation in a certain limit. The corresponding hyperbolic equations are studied and solved numerically using Godunov type methods. In [35], generalized solitary waves with exponentially small non-decaying oscillatory tails are constructed for a singularly-perturbed differential equation generalizing the higher-order KdV equation. In [36], the author studies collisions of any number of solitons and breathers in the Gardner equation with positive cubic nonlinearity. The magnification factor for the wave amplitude in the focal point is calculated exactly to show that this factor is greater when solitons have alternating polarities.

\section{REFERENCES}

[1] Grimshaw, R. (1970). The solitary wave in water of variable depth. J. Fluid Mech., 42, 639-656.

[2] Grimshaw, R. (1971). The solitary wave in water of variable depth. Part 2. J. Fluid Mech., 46, 611-622.

[3] Grimshaw, R. (1979). Slowly varying solitary waves. I Korteweg-de Vries equation. Proc. Roy. Soc., 368A, 359-375.

[4] Grimshaw, R. and Stewartson, K. (1979). Slowly varying solitary waves. II Nonlinear Schrödinger equation. Proc. Roy. Soc., 368A, 377-388.

[5] Grimshaw, R.H.J. (1977). The modulation of an internal gravity-wave packet, and the resonance with the mean motion. Stud. Appl. Math., 56, 241-266.

[6] Grimshaw, R. (1979). Mean flows induced by internal gravity wave packets propagating in a shear flow. Phil. Trans. Roy. Soc., 292A, 391-417.

[7] Grimshaw, R. (1981). Evolution equations for long nonlinear internal waves in stratified shear flows. Stud. Appl. Math., 65, 159-188.

[8] Grimshaw, R. (1984). Wave action and wave-mean flow interaction, with application to stratified shear flows. Ann. Rev. Fluid Mechanics, 16, 11-44.

[9] Grimshaw, R. (1985). Evolution equations for weakly nonlinear, long internal waves in a rotating fluid. Stud. Appl. Math., 73, 1-33.

[10] Gear, J. and Grimshaw, R. (1984). Weak and strong interactions between internal solitary waves. Stud. Appl. Math., 70, 235-258.

[11] Grimshaw, R. (1994). Resonant wave interactions near a critical level in a stratified shear flow. J. Fluid Mech., 269, 1-22.

[12] Grimshaw, R.H.J. and Smyth, N. F. (1986). Resonant flow of a stratified fluid over topography. J. Fluid Mech., 169, 429-464.

[13] Grimshaw, R. H. J., Zhang D.-H. and Chow, K. W. (2009). Transcritical flow over a hole. Stud. Appl. Math., 122, 235-248.

[14] Grimshaw, R., Pelinovsky, D., Pelinovsky, E. and Talipova, T. (2001). Wave group dynamics in weakly nonlinear long-wave models. Physica D, 159, 35-57.

[15] El, G.A., Grimshaw, R.H.J. and Kamchatnov, A.M. (2005). Wave breaking and the generation of undular bores in an integrable shallow-water system. Stud. Appl. Math., 114, 395-411.

[16] El, G.A., Grimshaw, R. H.J. and Smyth, N.F. (2006). Unsteady undular bores in fully nonlinear shallowwater theory. Phys. Fluids, 18, 027104 (17 pages). 
[17] Grimshaw, R., Pelinovsky, E., Talipova, T. and Kurkina, A. (2010) Internal solitary waves: propagation, deformation and disintegration. Nonlinear Processes in Geophysics, 17, 633-649.

[18] Grimshaw, R. H. J., Ostrovsky, L. A., Shrira, V. I. and Stepanyants, Yu. A. (1998) Long nonlinear surface and internal gravity waves in a rotating ocean. Surveys in Geophysics, 19, 289-338.

[19] Grimshaw, R. and Helfrich, K.R. (2008). Long-time solutions of the Ostrovsky equation. Stud. Appl. Math., 121, 71-88.

[20] Grimshaw, R., Helfrich, K. and Johnson, E. (2012) The reduced Ostrovsky equation: integrability and breaking, Stud. Appl. Math., 129, 414-436.

[21] Grimshaw, R., Helfrich, K. and Johnson, E. (2013). Experimental study of the effect of rotation on large amplitude internal waves. Phys. Fluids, 25, 056602.

[22] Akylas, T.R. and Grimshaw, R.H.J. (1992). Solitary internal waves with oscillatory tails. J.Fluid Mech., 242, 279-298.

[23] Grimshaw, R. and Joshi, N. (1995). Weakly non-local solitary waves in a singularly perturbed Korteweg-de Vries equation. SIAM J. Appl. Math., 55, 124-135.

[24] Gottwald, G. and Grimshaw, R. (1999). The formation of coherent structures in the context of blocking. J. Atmos. Sci., 56, 3640-3662.

[25] Nitsche, M., Weidman, P.D, Grimshaw,R., Ghrist, M. and Fornberg, B. (2010). Evolution of solitary waves in a two-pycnocline system. J. Fluid Mech., 642, 235-277.

[26] Alias, A., Grimshaw, R. H. J., Khusnutdinova, K. R. (2014) Coupled Ostrovsky equations for internal waves in a shear flow, Phys. Fluids, 26, 126603.

[27] Grimshaw, R. (2016). Nonlinear wave equations for oceanic internal solitary waves. Stud. Appl. Math., 136, 214-237.

[28] Grimshaw, R. and Yuan, C. (2016). The propagation of internal undular bores over variable topography. Physica D, 333, 200-207.

[29] Grimshaw, R. and Helfrich, K. R. (2018) Internal solitary wave generation by tidal flow over topography. J. Fluid Mech., 839, 387-407.

[30] Hoefer, M.A., Smyth, N.F. and Sprenger, P. (2019) "Modulation theory solution for nonlinearly resonant, fifth-order Korteweg-de Vries, non-classical, traveling dispersive shock waves" please insert full reference here

[31] Congy, T., El, G.A., Hoefer, M.A. and Shearer, M. (2019) "Nonlinear Schrödinger equations and the universal description of dispersive shock wave structure" please insert full reference here

[32] Ablowitz, M.J., Cole, J.T. and Rumanov, I. (2019) "On the Whitham system for the radial nonlinear Schrödinger equation" please insert full reference here

[33] Bridges, Th.J. and Ratliff, D.J. (2019) "Krein signature and Whitham modulation theory: the sign of characteristics and the sign characteristic" please insert full reference here

[34] Dhaouadi, F., Favrie, N. and Gavrilyuk, S. (2019) "Extended Lagrangian approach for the defocusing Non-Linear Schrödinger equation please insert full reference here

[35] Joshi, N. and Lustri, C.J. (2019) "Generalized Solitary Waves in a Finite-Difference Korteweg-de Vries Equation" please insert full reference here

[36] Slunyaev, A. (2019) "On the optimal focusing of solitons and breathers in long wave models" please insert full reference here 
Department of Mathematical Sciences, Loughborough University, Loughborough Le11 3TU, $\mathrm{UK}$

E-mail address: K.Khusnutdinova@lboro.ac.uk

Department of Mathematics and Statistics, McMaster University, Hamilton, Ontario, Canada, L8S $4 \mathrm{~K} 1$

E-mail address: dmpeli@math.mcmaster.ca 